\title{
Adenovirus serotypes isolated from ocular infections in London
}

\author{
S. DAROUGAR, ${ }^{\prime}$ P. WALPITA, ${ }^{1}$ U. THAKER, ${ }^{1}$ N. VISWALINGAM, ${ }^{2}$ \\ L. GARDNER, ${ }^{1}$ AND D. A. MCSWIGGAN ${ }^{3}$ \\ From the ${ }^{1}$ Subdepartment of Virology, Institute of Ophthalmology, Judd Street, \\ London WC1H 9QS; the ${ }^{2}$ External Eye Diseases Clinic, Moorfields Eye Hospital, \\ City Road, London EC1V 2PD; and the ${ }^{3}$ Department of Microbiology, Public Health Laboratory, \\ Central Middlesex Hospital, London NW10 7NS
}

SUMMARY During the period 1973-8 700 adenoviruses were isolated from the eyes of patients presenting at Moorfields Eye Hospital. Of these, 678 were serotyped by a neutralisation test. Twenty-one different serotypes were identified. Serotype 3, 7, and 10 accounted for $68 \%$ of the isolates, $4,8,15(15 / 29)$, and 19 for $25 \%$, and the other 14 serotypes for $7 \%$. Community outbreaks of ocular infections by adenovirus $3,4,7,10$, and $15(15 / 29)$ were observed. Outbreaks with adenovirus 3,7 , and 10 appeared to continue for 2 years or more, whereas outbreaks with 4 and 15 $(15 / 29)$ were restricted to one year or less. Hospital outbreaks by adenovirus 8 and 19 were also recorded. During the same period 18 of these 21 adenovirus serotypes were isolated from the nonocular sites (mainly respiratory tract) in 7804 cases. There was a close association in the distribution of adenovirus $1,2,3,5$, and 6 in the ocular and nonocular sites. No such association was observed for adenovirus serotypes 4, 8, 10, 15 (15/29), and 19.

In a previous study ${ }^{1}$ we reported clinical and epidemiological features of ocular infections caused by various adenovirus serotypes.

In this paper we report the distribution of adenovirus serotypes isolated from the eyes of patients presenting to Moorfields Eye Hospital, London, over the years 1973-8. This study has provided an opportunity to compare the distribution of adenovirus serotypes in ocular and nonocular (mainly respiratory) sites.

\section{Materials and methods}

Between 1973 and 1978700 adenovirus isolations were made in our laboratory from the eyes of patients presenting at Moorfields Eye Hospital, London. Conjunctival swabs were collected and cultured in HEp2 cells; methods of collection, transport, and storage of specimens, and virus isolation have been described previously. ${ }^{2}$ Virus serotyping was done by a standard neutralisation procedure with type-specific antisera.

Correspondence to Dr S. Darougar, Institute of Ophthalmology, Judd Street, London WC1H 9QS.

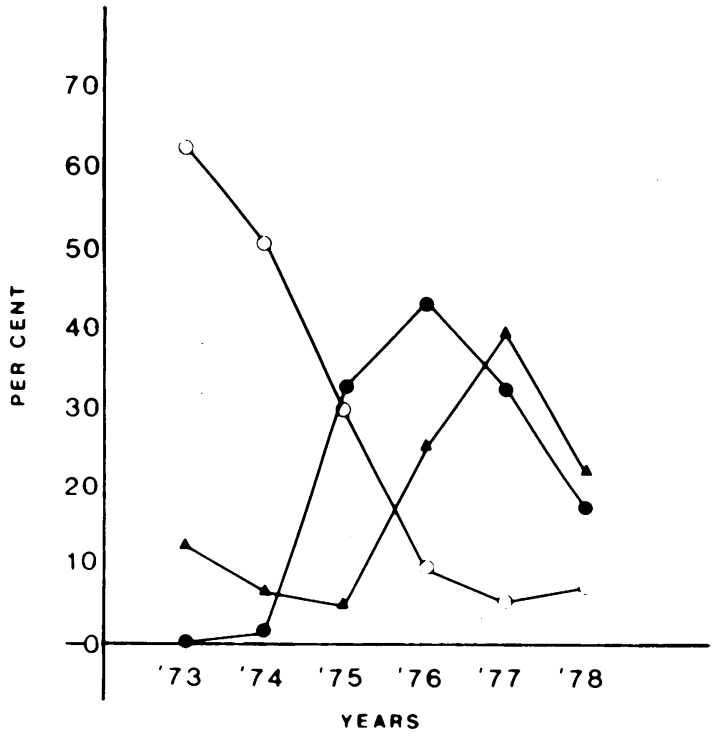

Fig. 1 Annual incidence of adenovirus serotypes 3, 7, and 10 (1 adenovirus 3, O adenovirus 7, adenovirus 10). 
Table 1 Annual distribution of ocular adenovirus serotypes: 1973-8

\begin{tabular}{|c|c|c|c|c|c|c|c|c|}
\hline \multirow[t]{2}{*}{ Serotype } & \multicolumn{6}{|l|}{ Year } & \multirow[t]{2}{*}{ Total } & \multirow{2}{*}{$\begin{array}{l}\% \text { of } \\
\text { total }\end{array}$} \\
\hline & 1973 & 1974 & 1975 & 1976 & 1977 & 1978 & & \\
\hline 1 & 2 & 0 & 1 & 4 & 1 & 1 & 9 & $1 \cdot 3$ \\
\hline 2 & 1 & 0 & 3 & 4 & 2 & 4 & 14 & $2 \cdot 1$ \\
\hline 3 & 9 & 5 & 6 & 38 & 53 & 27 & 138 & $20 \cdot 3$ \\
\hline 4 & 2 & 3 & 17 & 17 & 12 & 29 & 80 & $11 \cdot 8$ \\
\hline 5 & 0 & 3 & 1 & 1 & 0 & 0 & 5 & 0.74 \\
\hline 6 & 0 & 0 & 2 & 3 & 0 & 0 & 5 & 0.74 \\
\hline 7 & 45 & 38 & 36 & 15 & 7 & 9 & 150 & $22 \cdot 1$ \\
\hline 8 & 5 & 3 & 1 & 0 & 0 & 22 & 31 & $4 \cdot 5$ \\
\hline 9 & 0 & 0 & 1 & 0 & 0 & 0 & 1 & $0 \cdot 15$ \\
\hline 10 & 0 & 1 & 40 & 66 & 44 & 21 & 172 & $25 \cdot 3$ \\
\hline 13 & 0 & 0 & 0 & 0 & 0 & 1 & 1 & $0 \cdot 15$ \\
\hline 14 & 1 & 0 & 0 & 0 & 0 & 0 & 1 & $0 \cdot 15$ \\
\hline $15(15 / 29)$ & 1 & 0 & 6 & 1 & 10 & 0 & 18 & $2 \cdot 6$ \\
\hline 16 & 0 & 0 & 0 & 0 & 1 & 4 & 5 & $0 \cdot 74$ \\
\hline 17 & 0 & 0 & 1 & 0 & 0 & 0 & 1 & $0 \cdot 15$ \\
\hline 19 & 6 & 21 & 5 & 3 & 0 & 0 & 35 & $5 \cdot 1$ \\
\hline 21 & 0 & 1 & 1 & 0 & 0 & 1 & 3 & 0.44 \\
\hline 22 & 0 & 0 & 0 & 0 & 3 & 1 & 4 & 0.59 \\
\hline 24 & 0 & 0 & 0 & 0 & 1 & 0 & 1 & $0 \cdot 15$ \\
\hline 29 & 0 & 0 & 0 & 0 & 1 & 0 & 1 & $0 \cdot 15$ \\
\hline 30 & 0 & 0 & 1 & 0 & 0 & 2 & 3 & 0.44 \\
\hline Total & 72 & 75 & 122 & 152 & 135 & 122 & 678 & 100 \\
\hline
\end{tabular}

\section{Results}

OCULAR ISOLATES

Frequency. Of the 700 isolates 678 were typed, 12 were untypeable, and 10 were not available for typing. Twenty-one different serotypes were identified. Serotypes 3,7 , and 10 were predominant, accounting for $68 \%$ of the isolates; serotypes $4,8,15(15 / 29)$, and 19 accounted for $25 \%$; while the remaining 14 serotypes occurred infrequently and accounted for only $7 \%$ of the isolates (Table 1). Eighteen isolates were identified as serotype 15 , but 3 of these crossreacted with antiserum against serotype 29 . They are therefore presented as serotype 15 (15/29).

Annual incidence. The annual incidence of the 21 serotypes is shown in Table 1 . There was considerable fluctuation between the 3 predominant serotypes ( 3 , 7 , and 10) over the 5-year period (Fig. 1). During the first 2 years adenovirus 7 accounted for over half of all the isolates. However, it showed a marked decline from a peak position in $1973(62 \%)$ to only $7 \%$ of isolations by 1977. Adenovirus 3 and 10 showed an almost identical pattern of rise and fall separated by an interval of a year.

Adenovirus 4 distribution increased substantially during the last year of the survey. The remaining serotypes occurred relatively infrequently, and as a result little can be attributed to their pattern of variation.

Seasonal variation. Only 2 serotypes, namely, 7 and 10 , showed distinct seasonal variations, the former being more frequently isolated in the spring and the latter in the winter (Fig. 2).

Age and sex distribution. The majority of ocular adenovirus isolates $(66 \%)$ were from the age groups 20-40; only $15 \%$ were from patients below 20 years, and $19 \%$ from patients over the age of 40 (Fig. 3). Individual serotypes conformed to the general pattern of age distribution. Infection was commoner in males than in females (ratio 1.4 to 1 ).

Outbreaks. Community related outbreaks occurred due to serotypes $3,4,7,10$, and $15(15 / 29)$. Outbreaks due to serotype 3,7 , and 10 were very persistent, continuing for 2 or more years. Nosocomial transmission accounted for the majority of infections due to adenovirus 8 (1978) and adenovirus 19 (1973-4).

\section{NONOCULAR ISOLATES}

During the period 1973-8, 18 of the 21 ocular adenovirus serotypes were also isolated from nonocular sites in 7804 cases in England and Wales (Public Health Laboratory Service, unpublished data). Serotypes 13,29 , and 30 were not isolated from the nonocular sites. Serotypes 1,2 , and 7 were the most frequently reported in nonocular sites, accounting for $68 \%$ of isolations, while serotypes 3,4 , and 5 accounted for $29 \%$. The remaining 12 serotypes were infrequently reported. Marked annual fluctuations in isolation rates of the various serotypes occurred, some of which were associated with rises in ocular infection whereas others appeared unrelated (Fig. 2). Changes in the incidence of serotypes $1,3,5$, and 6 
from nonocular and ocular infections were closely related, whereas clusters of ocular infections due to adenovirus $4,8,10,15 .(15 / 29)$, and 19 were not associated with corresponding rises in nonocular infections due to these serotypes. Adenovirus 7 infections in general showed concomitant infections, but a number of clusters of nonocular and ocular infections occurred independently of each other.

\section{Discussion}

In this series $92 \%$ of ocular adenovirus infections (sporadic cases and outbreaks) were due to serotypes $3,4,7,8,10,15(15 / 29)$ and 19 . The remaining serotypes were associated only with occasional sporadic cases.

The outbreaks due to adenovirus 3 and 7 developed and declined slowly extending over several years (Fig. 2). The adenovirus 7 outbreak reported here appears to have been part of a very extensive outbreak during the early 1970 s which occurred not only throughout
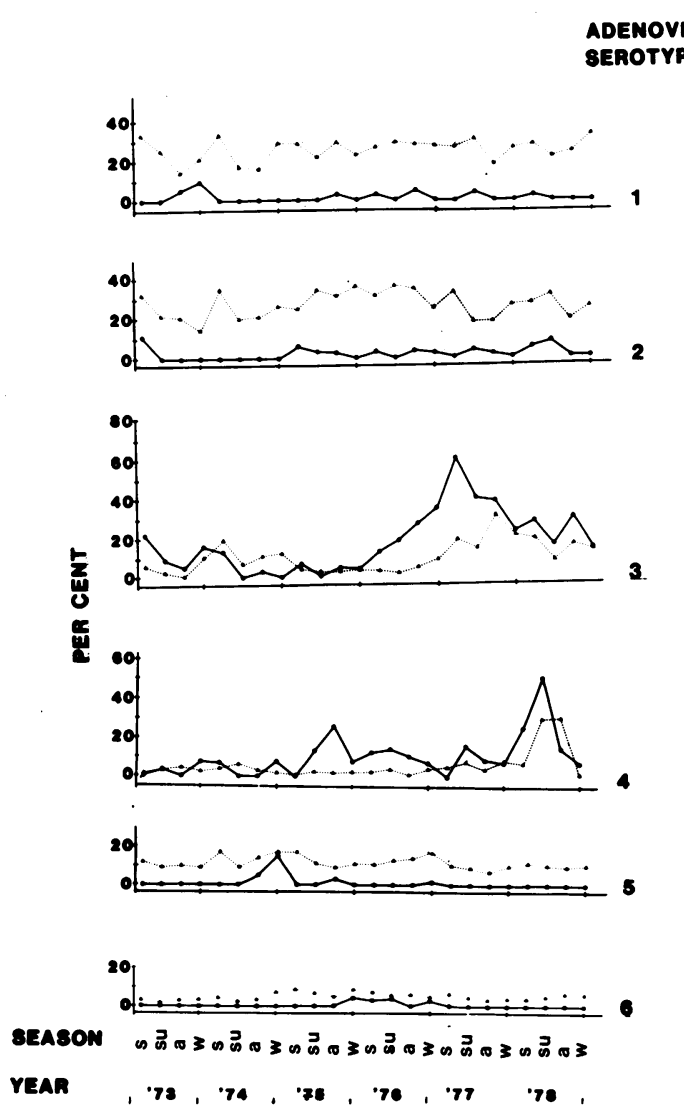

Fig. 2 Seasonal incidence of ocular and nonocular adenovirus serotypes during 1973-8. Solid line: ocular isolates. Broken line: nonocular isolates. $S=$ spring, $S u=s u m m e r, A=a u t u m n, W=$ winter. Serotype 15 includes 3 isolates of serotype
$15 / 29$.

this country ${ }^{3}$ but also affected Scandinavia ${ }^{4}$ and North America. ${ }^{5}$ It is of interest that this extensive outbreak was followed almost immediately by an adenovirus 3 outbreak, suggesting the possibility of cyclic interaction between these 2 serotypes. Such cyclic activity has been reported in respiratory infections with adenovirus 1 and $2 .^{\circ}$

An outbreak due to adenovirus 4 developed rapidly at the beginning of 1978 and persisted for the year. It coincided with a community outbreak in the Bristol area. $^{7}$

Although adenovirus 10 was detected only once in 1974 , an outbreak due to this serotype developed in 1975 and has continued since then, peaking each year in winter. Outbreaks on this scale due to adenovirus 10 have not been reported previously, though an outbreak associated with serotype $10 / 19$ was reported from Bristol during $1977-8 .^{8}$ Sporadic cases due to adenovirus 10 are rarely reported..$^{10}$

During 1973 an outbreak due to adenovirus 19 occurred; this involved both the local community and
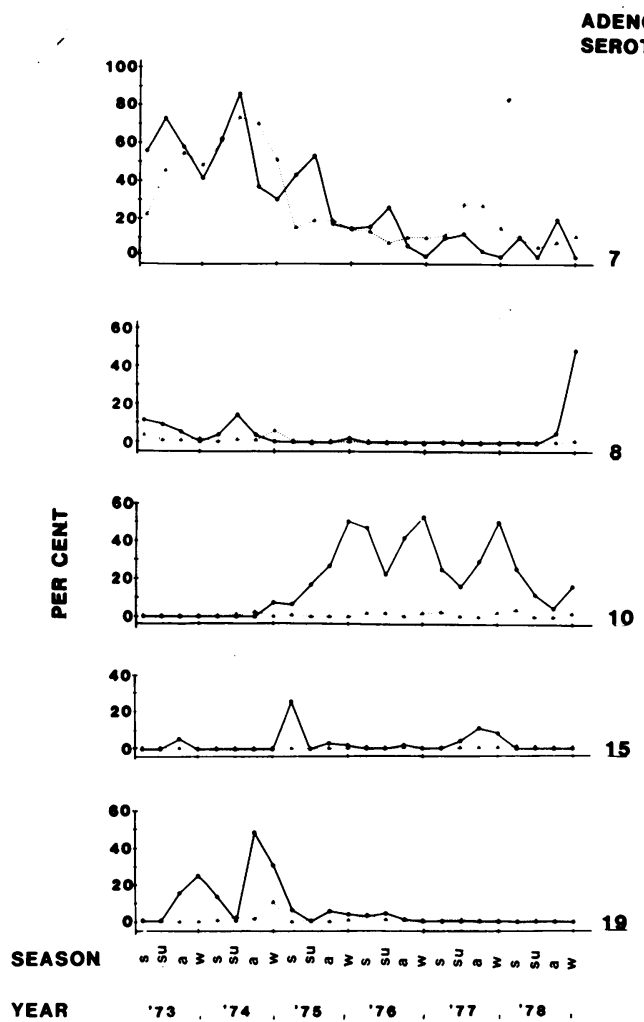

YEAR ENOVIRUS EROTYPE 15 


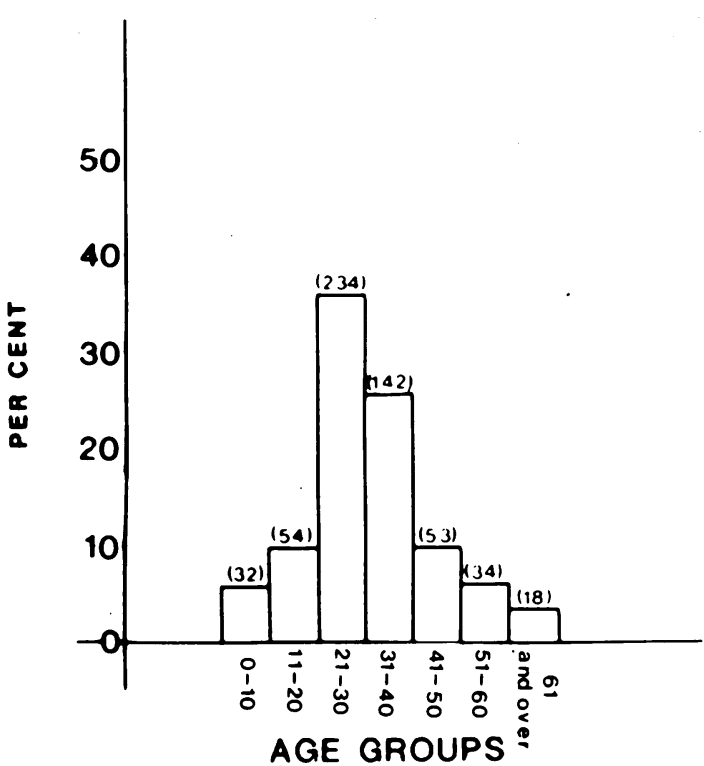

Fig. 3 Age distribution in patients with ocular adenovirus infections. Figures in parentheses indicate sample size.

the hospital. The outbreak extended into 1974, with some isolations being made during 1975 and 1976. Ocular infections during the same period were reported from the USA, ${ }^{11}$ Holland and Belgium, ${ }^{12}$ Canada,${ }^{13}$ and Scotland. ${ }^{14}$ During the last 2 years of this survey, however, this serotype has not been detected.

Two small clusters of infections caused by adenovirus $15(15 / 29)$ were detected, one in 1975 and the other in 1977. Ocular infection due to this serotype is rarely encountered. ${ }^{15}$

Only 2 adenovirus serotypes exhibited clear seasonal variations. Adenovirus 7 showed an early summer peak (April to June) each year, except 1978 when the peak was delayed to July-September. The peak incidence for adenovirus 10 on the other hand was consistently during the winter months (October to December).

It was of interest that certain adenovirus serotypes commonly associated with nonocular sites were rarely found in ocular infections. Adenovirus 1, 2, and 5, accounting for $55 \%$ of the nonocular infections, were seldom isolated from the eye. Conversely, adenovirus $4,8,10,15(15 / 29)$, and 19 , frequently isolated from the eye, were seldom reported from other sites. These findings suggest that for certain serotypes nonocular sites, particularly the respiratory tract, are not a major reservoir of virus for ocular infection.

We are indebted to the Communicable Disease Surveillance Centre, Colindale, for epidemiological data on nonocular adenoviruses and to the Division of Microbiological Reagents and Quality Control, Central Public Health Laboratory, for the supply of reagents.

This project was supported by grants from the Department of Health and Social Security and the Locally Organised Research Scheme, Moorfields Eye Hospital.

\section{References}

1 Darougar S, Grey RHB, Thaker U, McSwiggan DA. Clinical and epidemiological features of adenovirus keratoconjunctivitis in London. Br J Opthalmol 1983; 67: 1-7.

2 McSwiggan DA, Darougar S, Rahman AFMS, Gibson JA. Comparison of the sensitivity of human embryo kidney cells, Hela cells, and W138 cells for the primary isolation of viruses from the eye. J Clin Pathol 1975; 28: 410-3.

3 Sutton RNP, Pullen Hazel JM, Blackledge P, Brown EH, Sinclair L, Swift PN. Adenovirus type 7; 1971-74. Lancet 1976; ii: 987-91.

4 Simila S, Joupilla R, Salmi A, Pohjoneu R. Encephalomeningitis in children associated with an adenovirus type 7 epidemic. Acta Paediatr Scand 1970; 59: 310-6.

5 Brown RS, Nogrady MB, Spence LS, Wiglesworth FW. An outbreak of adenovirus type 7 infection in children in Montreal. Can Med Ass J 1973; 108: 434-9.

6 Fox JP, Brand CD, Wassermann FE, Hall CE, Spigland I, Deutsch DM, Kogon A, Elveback LR. The Virus Watch Programme: a continuing surveillance of viral infections in metropolitan New York families. Observations of adenovirus infection: virus excretion patterns, antibody response, efficiency of surveillance, patterns of infection and relation to illness. Am J Epidemiol 1969; 89: 25-50.

7 Tullo AB, Higgins PG. An outbreak of adenovirus type 4 conjunctivitis. Br J Ophthalmol 1980; 64: 489-93.

8 Tullo AB, Higgins PG. An outbreak of adenovirus keratoconjunctivitis in Bristol. Br J Ophthalmol 1979; 63: 621-6.

9 Heubner RJ, Rowl WP. Adenovirus as aetiological agents in conjunctivitis and keratoconjunctivitis. Am J Ophthalmol 1957; 43: 20-5.

10 Zografos L. La keratoconjunctivite de l'adenovirus type 10. Ophthalmologica 1977; 174: 61-64.

11 Hierholzer JC, Guyer B, O'Day DM, Shaffner W. Adenovirus type 19 keratoconjunctivitis. N Engl J Med 1974; 290: 1436.

12 Desmyter J, Dejong JC, Slaterus KW, Verlaeckt H. Keratoconjunctivitis caused by adenovirus type 19 . $\mathrm{Br}$ Med $J 1974$; iv: 406.

13 Vas SI, Abramovitch H, Jackson WB, Dickson C, Groh V, Champlin R. Keratoconjunctivitis due to adenovirus type 19Canada. Morbidity and Mortality Weekly Reports 1974; 24: 185-6.

14 Bell EJ, Winton FW. Keratoconjunctivitis caused by adenovirus type 19. Br Med J 1975; i: 91.

15 Editorial: Adenovirus keratoconjunctivitis. $\mathrm{Br} J$ Ophthalmol 1977; 61: 73-5. 